\title{
Self-Esteem, Needs Satisfaction and Psychological Well-Being of Inmates at James Camp Prison in Ghana
}

\author{
Daniel Bruce ${ }^{1}$, Elizabeth Larweh ${ }^{2}$ \\ ${ }^{1,2}$ Methodist University College Ghana, Department of Psychology, Dansoman- Ghana \\ *Corresponding Author: Daniel Bruce, Methodist University College Ghana, Department of \\ Psychology, Dansoman- Ghana
}

\begin{abstract}
The purpose of this study was to find out the relationship between the self-esteem, needs satisfaction and the psychological well-being of prisoners. The study employed the correlation survey design method to solicit information from respondents who are prisoners in the James Camp Prison in Accra. The random sampling technique was used to select 155 male prisoners from an estimated population of 347 . The findings revealed the following; a significant positive correlation exists between self-esteem, needs satisfaction and psychological well-being among inmates. The length of prison sentence has no effect on prisoners' psychological well-being; there was no significant effect of visits by family and friends on prisoners' psychological well-being. It is, therefore, recommended that, counselling should be strengthened in the prisons to help reduce the psychological effects of imprisonment on inmates.
\end{abstract}

Keywords: Self-esteem, Needs Satisfaction, Psychological Well-Being, Inmates, and Prison.

\section{INTRODUCTION}

Charles Montaldo (2014), a Private Detective who has worked in various areas of crime detection says, 'crime occurs when someone breaks the law by an overt act, omission or neglect that can result in punishment'. A person who has violated a law, or has breached a rule, is said to have committed a criminal offense. No matter one's reason for committing a particular crime, when caught and convicted, he/she does not go unpunished. The punishment as established earlier ranged from fines to short or long term imprisonment, otherwise known as incarceration. Generally speaking, Prisons are often perceived as scenes of brutality, violence and stress.

Prisoners are faced with incidence of violence and are always concerned for their safety. Tosh (1982:86), quoted a long-term prisoner named Jack Abbott as stating that in the prison, "everyone is afraid, it is not an emotional or psychological fear but it is a practical matter. If you don't threaten someone at the very least, someone will threaten you." Many times, you have to "prey" on someone or you will be "preyed" on yourself." Prisons aim to cure criminals of crime. However, their records and personal observations have not been encouraging. Instead, prisons do more harm than good. The pains of jail confinement affect all prisoners in different ways.

Tosh (1982) noted that, prisoners need to withstand the entry shock by adapting quickly to prison life. Prisoners are exposed to a new culture, which is very different from their own culture. Then they need to maintain outside links. For example, keeping in contact with family and friends becomes frustrating. While being in prison, the prisoner must determine his/her ways of passing the time since the hours appear endless.

For some prisoners, the major source of stress would include the loss of contact with family and friends outside the prison. There is also the fear of deterioration. There is lack of personal choice within the prison environment which may affect prisoners. After many years of being told what to do, they may well lose the ability to think for themselves and make their own decisions and choices freely (Tosh: 1982).

Ghana, just as other countries in the world has a number of prisons known as correctional centres where criminals/offenders are kept. Adu (2007) posits that, crime is still an ever-present occurrence in Ghana in spite of several efforts made by government and other agencies to clamp down on criminals 
and improve human and social security of Ghanaians. This he said is because, the country's prison facilities where criminality is expected to end have become revolving doors and that, too many of their residents, prisoners, return time and again. According to him, more than half of all inmates will be back in prison within six years of their release. He further mentioned that, it was sad but very unfortunate that the prison facilities across the country, whatever form they take do not seem to correct, rehabilitate or treat criminal offenders to become useful citizens at the end of their jail terms. He said they rather make them more embittered because of the degrading human conditions such as insufficient food, water, clothing, medicals and detergents.

Prisons in Ghana are classified based on their level of security, and on the activities undertaken at the various establishments. In the Central Prisons, trade training facilities are provided to equip prisoners with employable skills for their effective reintegration into society. They take custody of longsentenced prisoners. Central Prisons are for all categories of prisoners, with the exception of condemned prisoners. Local Prisons are mainly for the safe custody and welfare of inmates. They usually take custody of short-sentenced prisoners. Open Camp Prisons undertake agricultural activities to provide food and train inmates in modern agricultural practices.

Self-esteem is crucial and is a cornerstone of a positive attitude towards living. It is very important because it affects how one thinks, acts and even how a person relates to other people. Low self-esteem means poor confidence and that also causes negative thoughts which mean that, the individual is likely to give up easily rather than face challenges. In addition, it has a direct bearing on one's happiness and wellbeing. Maslow, posits that without the fulfillment of the self-esteem need, individuals will be driven to seek it and unable to grow and obtain self-actualization. Maslow(1987). Abraham Maslow established a link between self - esteem and psychological well-being.

Imprisonment can have adverse effects on prisoners' self-esteem. One of these effects, according to Craig (2001), is a diminished sense of self-worth and personal value. He says prisoners typically are denied their basic privacy rights, and lose control over mundane aspects of their existence that most citizens have long taken for granted. They live in small, sometimes extremely cramped and deteriorating spaces, have little or no control over the identity of the person with whom they must share that space, often have no choice over when they must get up or go to bed, when or what they may eat, amongst others. A diminished sense of self-worth and personal value may result. In extreme cases of institutionalization, prisoners may come to think of themselves as "the kind of person" who deserves only degradation and stigma to which they have been subjected while incarcerated.

\section{RELATIONSHIP BETWEEN IMPRISONMENT AND NEEDS SATISFACTION}

Generally speaking, imprisonment basically takes away prisoners' rights to satisfy the psychological needs of life. These needs are the needs for autonomy, competence and relatedness (Craig, 2001). This may affect their satisfaction of the need for relatedness. There is lack of personal choice within the prison environment which may affect prisoners need for autonomy. Also, after many years of being told what to do they may well lose the ability to think for themselves and make their own decisions and choices freely (Tosh, 1982).

\section{EFFECTS OF IMPRISONMENT ON PRISONERS' PSYCHOLOGICAL WELL-BEING}

Imprisonment is likely to have numerous effects on prisoners' psychological well-being. Jenny Krestev et al (2005) presented these effects by tracing them from time past. Historically, imprisonment was based on punishing those who wronged society, by inflicting suffering on the body similar to the pound of flesh depicted within Shakespeare's "Merchant of Venice." In contrast to this concept, today's imprisonment is no longer simply intended as an acute form of corporal punishment, but a method by which to work on a person's mind as well as his body, through three distinct areas which include, punishment, deterrence, and rehabilitation. These three unique areas, when interlinked into a single process, are intended to allow society to remove criminals from a position where they may continue their criminal behaviour, place them into an institution that satisfies the masses who desire some form of retribution, persuade other would be criminals that such activities are not beneficial, and in time sculpt them into productive and law abiding citizens through positive psychological conditioning who may later be re-integrated into society. 
A number of researchers concluded that imprisonment had negative psychological and physical effects on its inmates, leading to psychological deterioration. These effects included emotional withdrawal, (Clement, 1979) depression, (Cooper, 1974) suicidal thoughts or actions (Flanagan, 1980) and increasing levels of hostility (Bolton \& Heskin, 1976). Modern research works also seem to conclude that the most damaging factor to inmates are the loss of their life in the outside world and relations with family, rather than the actual regime or conditions of imprisonment (MacKenzie \& Mitchell, 2005, Yang, et al.,2009).

In view of the above listed challenges faced by prisoners, there is therefore the need to investigate the relationship between prisoners' self-esteem, needs satisfaction and psychological well-being and determine the influence of prison sentence and the impact of visitation on prisoners' psychological well-being. This is what this research intends to achieve.

\section{STATEMENT OF HyPOTHESIS}

The following hypotheses will be tested in relation to the aim of the study;

1. There will be a significant positive correlation between psychological well-being and self-esteem of prisoners.

2. There will be a significant positive correlation between needs satisfaction and psychological wellbeing of prisoners.

3. There will be a significant positive correlation between self-esteem and needs satisfaction of prisoners.

4. Prisoners with short sentences will show a healthier psychological well-being compared to those with long sentences.

5. Prisoners who are visited by family members will exhibit a healthier psychological well-being than those who are not visited by family members

\section{Methodology}

\subsection{Research Design}

The research design used was correlational survey. It was chosen because it will help to figure out how the variables (self-esteem, needs satisfaction and psychological well-being) are connected to each other.

\subsection{Target Population}

The target population was all male prisoners with varied educational, economic, religious and social background of the James Camp Prison in Accra. The total population of the prisoners in the camp was 347.

\subsection{Sampling Technique}

The Epi Info version 3.5.1 was used to determine the sample size of the research.

Population Size

Expected Frequency

Worst Acceptable Value

Confidence Level

Estimated Representative Sample
347

$$
10 \%
$$

$99 \%$

141

However, to make room for inappropriate completion and non return of the questionnaire, 14 (more than $10 \%$ ) participants were added to round the figure up to 155 . Based on this formula, a random sampling technique was used to choose one hundred and fifty-five prisoners. A basket containing folded papers with 'YES' and 'NO' written on them was presented to the participants. Each member of the population was made to pick one of the folded papers. All those who picked 'YES' automatically became the subjects for the study. 


\section{INSTRUMENT / MATERIAL}

The instruments used for the study included:

\section{- Rosenberg Self-Esteem Scale}

It includes 10 items that are scored by attaching a four-point response ranging from "strongly disagree" to "strongly agree". Scores are calculated as follows: For items 1, 2, 4, 6, 7: strongly agree = 3 , agree $=2$, disagree $=1$, strongly disagree $=0$. For items $3,5,8,9,10$ : strongly agree $=0$, agree $=1$, disagree $=2$, strongly disagree $=3$. The scale has been shown to be reliable with a Cronbach's alpha range from .77 to .88

\section{- Basic Psychological Needs Scale}

The scale has 21 items concerning the three needs for competence, autonomy, and relatedness. It has been shown to be reliable, with Cronbach alphas of about 0.75. (Deci and Ryan 1985) The basic psychological need satisfaction scale was scored by attaching a score of 1-4 to the likert scales of "not at all" to "untrue".

\section{- The Ryff Scales of Psychological Well-Being}

The scale specifically focuses on measuring multiple facets of psychological well-being. These facets include: self-acceptance, the establishment of quality ties to others, a sense of autonomy in thought and action, the ability to manage complex environment to suit personal needs and values, the pursuit of meaningful goals and a sense of purpose in life and a continued growth and development as a person. A pilot study was conducted on thirty male prisoners to establish the reliability of the scale and a cronsbach co-efficient estimated was .76. The Ryff Psychological Well-Being scale was scored by attaching a score of 1-6 to the likert scales of "strongly disagree" to "strongly agree".

\section{Data Analysis}

The Statistical Package for the Social Sciences (SPSS) version 16 and descriptive statistics were used for the analysis of data.

\section{Procedure}

Institutional approval was sought from the Acting Director of Prisons and after the Officer in Charge (OIC) of the James Camp prisons was asked to allow entry in to the James Camp Prison the questionnaires were administered to the 155 respondent-prisoners in the James Camp Prison. Those who could read and write were given 30 minutes to complete the questionnaires. Participants who could not read the questions on the questionnaires were helped by reading and interpreting for them in their preferred Ghanaian language.

\section{RESULTS}

As revealed in table 1 below, a significant positive correlation exists between psychological wellbeing and self-esteem $[\mathrm{r}=.433]$, a significant positive correlation exists between psychological wellbeing and needs satisfaction [ $\mathrm{r}=.717]$, and a significant positive correlation exists between selfesteem and needs satisfaction $[\mathrm{r}=.591]$. The significant correlation between the three variables implies that a multiple regression analysis needs to be conducted to test the three hypotheses. Further, the two variables (self-esteem and needs satisfaction] control 51.5\% variability in the psychological well-being [ODD Ratio $=\mathbf{. 5 1 5}]$. This is significant as indicated by the ANOVAs/F ratio $\left[\mathbf{F}_{(\mathbf{2}, 152)}=\right.$ 80.605, $p=.000]$.

Table1. Correlation between Psychological Well-being, Self-Esteem and Needs Satisfaction

\begin{tabular}{|l|l|l|l|}
\hline \multicolumn{1}{|c|}{ Prisoners $(\mathbf{n}=155)$} \\
\hline \multicolumn{1}{|c|}{ Variables } & \multicolumn{1}{|c|}{$\mathbf{2}$} & \multicolumn{1}{c|}{$\mathbf{3}$} \\
\hline $\begin{array}{l}\text { Psychological Well-being } \\
\text { Self-Esteem - }\end{array}$ & - & $.433^{*}$ & $.717^{*}$ \\
\hline Needs Satisfaction & - & & $.591 *$ \\
\hline
\end{tabular}

Notes:

*significant at .05

1. Psychological Well-being

2. Self-Esteem

3. Needs Satisfaction 
Self-Esteem, Needs Satisfaction and Psychological Well-Being of Inmates at James Camp Prison in Ghana

Results from Standard Multiple Regression Analysis following analysis from table 1 above are presented in table 2 below

Table2. Standard Multiple Regression Analysis on relationship between psychological well-being, self-esteem and needs satisfaction of prisoners

\begin{tabular}{|l|l|l|l|l|}
\hline \multicolumn{1}{|c|}{ Variables } & \multicolumn{1}{|c|}{ B } & \multicolumn{1}{c|}{ t } & Seta \\
\hline Psychological Well-being & 11.331 & - & 2.411 & .017 \\
Self-Esteem & 3.026 & .214 & 3.198 & .043 \\
\hline Needs Satisfaction & 2.731 & .709 & 10.127 & .000 \\
\hline
\end{tabular}

Results in table 2 above, showed that significant positive correlation exists between psychological well-being and self-esteem $[\mathbf{t}=\mathbf{3 . 1 9 8}, \mathbf{p}=\mathbf{. 0 4 3}$. Results further indicate that self-esteem controls $\mathbf{2 1 . 4 \%}$ changes/variability in psychological well-being [Beta $=\mathbf{. 2 1 4}]$. Thus the first hypothesis which states that "there will be a positive correlation between psychological well-being and self-esteem was supported by the results of the analysis.

Hypothesis two states that "there will be a significant positive link between needs satisfaction and psychological well-being". Result from table 2 above further revealed a significant positive correlation between needs satisfaction and psychological well-being $[\mathbf{t}=\mathbf{1 0 . 1 2 7}, \mathbf{p}=\mathbf{. 0 0 0}]$. Needs satisfaction is revealed to control 70.9\% changes/variability in psychological well-being [Beta $=$ .709]. Thus the second hypothesis was supported.

Results in table 2, revealed that the correlation between self-esteem and needs satisfaction is positive and significant $\left[\mathbf{r}_{(\mathbf{1 5 3})}=\mathbf{. 5 9 1}, \mathbf{p}=\mathbf{. 0 0 0}\right]$. This implies that, the third hypothesis which states that, "there will be a significant positive correlation between self-esteem and needs satisfaction" is also supported by the result of the analysis.

The fourth and the fifth hypotheses states that "Prisoners with short sentences will show a healthier psychological well-being as compared to those with long sentences." and "Prisoners who are visited by family members will exhibit a healthier psychological well-being than those who are not visited by family members". Relevant information on these hypotheses is presented in table 3 below.

Table3. Univariant Table on Effect of Duration of Imprisonment and Visiting Status on Psychological Wellbeing of Prisoners

\begin{tabular}{|l|l|l|l|l|l|}
\hline \multicolumn{7}{|c|}{ Prisoners (n=155) } \\
\hline \multicolumn{1}{|c|}{ Groups } & M & SD & df & F & Sig \\
\hline Duration of imprisonment & 67.88 & 10.00 & & & \\
Short Period & 67.10 & 12.65 & 1,151 & 3.03 & .083 \\
Long Period & & & & & \\
\hline Visiting Status & 68.50 & 9.93 & & & \\
Visited & 66.91 & 11.98 & & .1 .84 & .176 \\
Not Visited &
\end{tabular}

Results in table 3 above shows that, the mean psychological well-being scores for prisoners serving short and long term are 68.50 and 66.91 with the SD of $\mathbf{1 0 . 0 0}$ and 12.65 respectively. These means were subjected to univariance analysis and the result, as shown in table 3 indicates that, no significant difference exists between prisoners with short and long jail terms. Therefore, the hypothesis which stated that prisoners with short sentences will show a healthier psychological well-being as compared to those with long sentences is not supported.

Results in Table 3 also revealed that the mean scores for prisoners who are visited by family members and those who are not visited are 68.90 and 66.91 with the SD of 9.93 and 11.98 respectively. The means were subjected to univariance analysis and the results as shown in table 3 indicates that, no significant difference exists between prisoners who are visited and those who are not visited by family members. Therefore, the hypothesis which stated that prisoners who are visited by family members will exhibit a healthier psychological well-being than those who are not visited by family members was also not supported.

\section{DISCUSSION}

The study investigated the relationship between the self-esteem, needs satisfaction and psychological well-being of prisoners and discussion of results is as follows; 
The first hypothesis "There will be a significant positive correlation between psychological wellbeing and self-esteem" was supported and results further indicate that self-esteem controls $21.4 \%$ changes/variability in psychological well-being. The findings supports Ryff (1996) work in which he stated that, an individual who exhibits mastery over all the aspect of Psychological Well-Being (SelfAcceptance, Purpose in life, Positive relationships, Personal growth, Autonomy, Environmental Mastery) will possess a positive self-esteem. Certainly Self-esteem is crucial and is seen as a cornerstone of a positive attitude towards living. Abraham Maslow (1979) established a link between self- esteem and psychological well-being. According to him, psychological health is not possible unless the essential core of the person is fundamentally accepted, loved and respected by others and by him or herself. Those who have high self-esteem are presumed to be psychologically happy and healthy (Taylor \& Brown, 1988). Having high self-esteem apparently provides benefits to those who possess it, they feel good about themselves, they are able to cope effectively with challenges and negative feedback, and they live in a social world in which they believe that people value and respect. Therefore, an individual who possesses a high self-esteem is likely to exhibit a healthy psychological well-being hence the correlation positive between the two variables. Since our prisoners to not have good psychological well-being, it follows that they have low self-esteem.

Hypothesis two stated that, "There will be a significant positive correlation between needs satisfaction and psychological well-being" was also supported and the analysis further revealed that needs satisfaction control $70.9 \%$ changes/variability in psychological well-being. This finding is in line with Deci \& Ryan (2002), that these three psychological needs (competence, autonomy, and psychological relatedness) motivate the self to initiate behaviour and specify nutriments that are essential for psychological health and well-being of an individual. Therefore, when the satisfaction of these needs is thwarted the individual may not function well.

Craig (2001) posits that imprisonment basically takes away prisoners rights to satisfy the psychological needs of life, which are the needs for autonomy, competence and relatedness. Prisoners typically are denied their basic privacy rights, and lose control over mundane aspects of their existence, for some prisoners, the major source of stress would include the loss of contact with family and friends outside the prison and this may affect their satisfaction of the need for relatedness. There is lack of personal choice within the prison environment which may affect prisoners' need for autonomy. Also, after many years of being told what to do they may well lose the ability to think for themselves and make their own decisions and choices freely (Tosh, 1982). All these factors according to Ryff have a bearing on one's psychological well-being hence the positive correlation between needs satisfaction and psychological well-being. This is the plight of the Ghanaian prisoner.

The third hypothesis, which states that, "there will also be a significant positive correlation between self-esteem and needs satisfaction" was also supported by the results of the analysis. Bonet (1997) posits that nothing in the way we think, feel, decide and act escapes the influence of self-esteem. Needs satisfaction involves the fulfillment of the needs of autonomy (that is the universal urge to be the causal agents of one's life and actions in harmony with ones integrated self), competence (which has to do with the universal want to interact, be connected to and experience caring for others) and relatedness (this has to do with seeking to control outcome and experience mastery). Therefore, an individual who is able to fulfill all these needs will have a positive self -esteem. The importance of self-esteem lies in the fact that it concerns ourselves, the way we are and the sense of our personal value. Thus, it affects the way we are and act in the world and the way we are related to everybody else hence the positive correlation between the two variables. It can be inferred that, the Ghanaian prisoners' inability to have their needs satisfied, made the develop low self-esteem.

The fourth hypothesis states that "Prisoners with short sentence will show a healthier psychological well-being compared to those with long sentences" This was not supported by the results of the analysis. Imprisonment definitely affects the psychological well-being of the prisoner whether the prison sentence is of shorter or longer duration.

The fifth hypothesis which states that "Prisoners who are visited by family members will exhibit a healthier psychological well-being than those who are not visited by family members" was not supported by the results of the analysis. This finding contradicts the findings of Wooldredge, J.D. (1999) who examined how inmate psychological well-being is influenced by participation in institutional programmes, frequency of visitation with outsiders, and experiences with victimization 
during incarceration and found out that, healthier attitudes correspond with greater programme participation, more frequent visitation, and no experience with victimization. The prison environment in Ghana is not likely to be those found in the advanced countries where the prison environment is designed to let the prisoner go through self experience and exploration leading to experiencing change in the unacceptable social behaviour that sent him to prison. The unconditional positive regard, acceptance and empathic prison environment that should be ideal therapeutic characteristics of prison environment cannot be identified with prison environments in Ghana. Prisoners are already perceived as social misfits and negatively labelled by society at large, families and friends. No matter the frequency of visitations by family and friends, the psychological scar is already deep in the personality of the short term or long term prisoner. Therefore, the psychological well-being of the Ghanaian prisoner is not feasible.

Looking at the prison environment and conditions in Ghana, it is unlikely that Ghanaian prisoners would enjoy sufficient needs satisfaction, high self-esteem and psychological well-being. This is because by the terms and conditions of imprisonment, prisoners are denied their basic privacy rights, needs for autonomy, competence, relatedness, control over choice of when to get up or go to bed, when or what to eat and contact with family and friends. The Ghanaian prisoner is likely to exhibit the following low self-esteem characteristics such as; have little faith in one's ability to achieve, become socially anxious and ineffective, view interpersonal relationships as threatening, feel less positively toward others, lacking confidence in their own judgment and opinions and expect others to reject them (Michener, DeLamater, \& Myers, 2004). Owing to the low self-esteem, the Ghanaian prisoner would develop unhealthy psychological well-being resulting in negative self perception, poor mental health, ineffective relationship with others, loss of purpose in life and ineffective personal growth. A prisoner's psychological well-being, needs satisfaction and self-esteem is not likely to improve by the visits from relatives, friends and well wishers. One could see the overall effect of imprisonment and therefore, the reason educating people to avoid engaging in socially unacceptable behaviours that will lead them to imprisonment.

\section{CONCLUSION}

The study investigated the relationship between self-esteem, needs satisfaction and psychological well-being of prisoners. Results showed that positive correlation exists between self-esteem, needs satisfaction and psychological well-being. In all, the Ghanaian prisoner lacks needs satisfaction, inadequate psychological well-being and low self-esteem. Therefore, the reformation or change of the unacceptable behaviour that brought these prisoners into prison for a given period of time may remain unchanged even after they are released from prison.

\section{RECOMMENDATION}

The study recommends that counselling should be strengthened in our prisons to help reduce the psychological effects of imprisonment on inmates. In doing this, programmes which will best match offenders to their needs must be established which may include; cognitive distortion restructuring, substance/drug-abuse treatment, anger management, decision making processes and techniques, behaviour modification, prison stress management, employable skills training and conflict resolution. In addition, prison officers must exhibit unconditional positive regard attitude to all manner of prisoners. This can help improve the prisoners' self-esteem, psychological well-being and their easy integration into society.

\section{REFERENCES}

[1] Adu, K. E.,(2007).Ghanas Prisons are human warehouses. Retrieved from http://www.ghanaweb.com/ Ghanahomepage/features/Ghana-s-Prisons-are-human-warehouses-130615

[2] Bolton, N., Smith, F.V., Heskin, K.J, \& Banister, P.A.,(2013). Psychological correlates of long-term imprisonment:IV. A longitudinal analysis. The British Journal of Criminology, 16(1), 38-47.

[3] Bonet, J. (1997). Se amigo de ti mismo: manual de autoestima. (Ed). Sal Terrae. Maliano (Cantabria, Espana)

[4] Breen, J. (2008). The ripple effects of imprisonment on prisoners' families. Working Notes, 57, $19-24$

[5] Charles, M.(2014). Definition of crime. Retrieved from: Crime .about.com/od/crime-101/a/what-Is-ACrime.htm

[6] Clements, C.B. (1979). Crowded prisons. Law and Human Behavior,3(3), 217-225 
[7] Cooper, H.H. (1974). The all pervading depression and violence of prison life. International Journal of Offender Therapy and Comparative Criminology.

[8] Craig, H., (2001). The Psychological Impact of Incarceration: Implication for Post-Prison Adjustment. University of California, Santa Cruz. Retrieved from http://aspe.hhs.gov/basic-report/psychologicalimpact-incareation-implication-post-prison-adjustment.

[9] Deci, E. L., \& Ryan, R. M.,(2000). The "what" and "why" of goal pursuits: human needs and the selfdetermination of behavior. Psychological inquiry. 11, 127-268.

[10] Flanagan, T.J. (1980). The pains of long-term imprisonment. British Journal of Criminology 20(2): 148156.

[11] Johnson, R. (1996). Hard time-understanding and reforming the prison. California. Wadsworth Publishing Company.

[12] Krestev, J., Prokipidis, P., \& Sycamnias, E. (2005). The psychological effects of imprisonment. Retrieved from On http:/www.uplink.com/lawlibrary.

[13] Mackenzie, D.L.,\& Mitchell, F.N.(2005). Inmates' experiences in prisons: Different perspetives. Journal of Contemporary Criminal Criminal Justice. 21(4) 309.

[14] Maslow, A.H.(1987). Motivation and personality. (3ed). New York, Harper \& Row.

[15] Michener, A. H., DeLamater, D.J.,\& Myers, D.J.(2004). Social psychology. Belmont, CA: Wadsworth/ Thomas Learning.

[16] Ryff, C.,(1989). Happiness is everything, or is it? Explorations on the meaning of Psychological WellBeing. Journal of Personality and social Psychology 57, 1069-1081 217-224.

[17] Taylor, S.E., Brown, J.D.(1988). Illusion and well-being: A social psychological perspecrive on mental health. Psychological Bulleting. 103, 193-210.

[18] Tosh, J.,(1982). The Pains of Imprisonment. California: Sage Publications.

[19] Yang, S., Kadouri, A., Revah-Levy, A., Mulvey, E.P., \& Falissard, B.(2009). Doing time: A qualitative study of long-term incarceration and the impact of mental illness. International Journal of Law and Psychiatry. 3432(5), 294-303.

\section{AUTHORS' BIOGRAPHY}

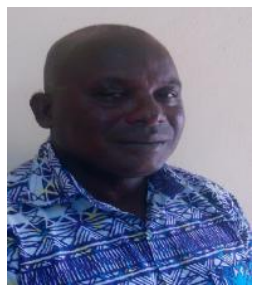

Dr. Daniel Bruce, is a trained Clinical Psychologist and Clinical Counsellor. He Holds a B.Ed (Hons) Psychology degree from University of Cape Coast; Masters of Philosophy (Clinical Psychology) from University of Ghana, Legon and a $\mathrm{PhD}$ in Clinical Christian Counselling from International Theological Seminary in Bradenton Florida, USA. He holds clinic for institutions, individuals, schools and organizations in such specialist areas as cognitive-behaviour therapy, marriage guidance and counselling, psycho - education assessment and intervention therapy for school related problems and behaviour modification among others. He is a Senior lecturer in Psychology at Methodist University, Ghana. He has a good number of published research articles in reputable journals worldwide. He is the author of Marriage Guidance and Counselling; A handbook for Marriage Counsellors and Pastors \& Parenting Techniques and Practices.

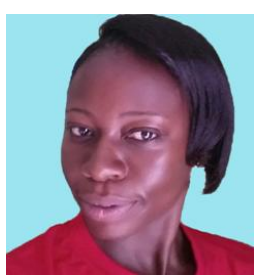

Miss Elizabeth Larweh, holds a Masters Degree in Guidance and Counselling from the Methodist University College of Ghana. She also holds Post Graduate Diploma in Education from University of Cape Coast and Bachelors Degree in Theatre Arts from the University of Ghana, Legon. She currently works with Green Community Better Life Foundation, a Non-Governmental Organization in Accra.

Citation: Daniel Bruce and Elizabeth Larweh, Self-Esteem, Needs Satisfaction and Psychological Well-Being of Inmates at James Camp Prison in Ghana, International Journal of Humanities Social Sciences and Education (IJHSSE) ), vol 4, no. 9, 2017, pp. 32-39. doi:dx. doi.org/10.20431/2349-0381.0409005.

Copyright: () 2017 Authors. This is an open-access article distributed under the terms of the Creative Commons Attribution License, which permits unrestricted use, distribution, and reproduction in any medium, provided the original author and source are credited. 